\title{
Cytotoxicity and proinflammatory effects of titanium and zirconia particles
}

\author{
Frank Schwarz ${ }^{1,2^{*}} \mathbb{D}$, Maike Langer ${ }^{1,2}$, Tina Hagena ${ }^{2}$, Brigitte Hartig ${ }^{2}$, Robert Sader ${ }^{3}$ and Jürgen Becker ${ }^{2}$
}

\begin{abstract}
Background: To assess the effects of differently sized titanium (Ti) and zirconia ( $\mathrm{Zr}$ ) particles on (1) the metabolic activity of osteosarcoma-derived osteoblasts (SaOs-2) and human gingival fibroblasts (HGF) and (2) the cytokine expression of monocytes (THP-1)

Methods: $\operatorname{Ti}(60-80 \mathrm{~nm}$ and $100 \mathrm{~nm})$ and $\mathrm{Zr}(2 \mu \mathrm{m}$ and $75 \mu \mathrm{m})$ particles were incubated with SaOs-2, HGF, and THP-1 cells. At days $0,2,4$, and 7 and 0, 1, 2, and 4 (THP-1), the mitochondrial activity was assessed and enzyme-linked immunosorbent assays were used to determine interleukin (IL)-1 beta and IL-6 concentrations of stimulated THP-1 at day 1.

Results: Ti60-80, Ti100, Zr2, and Zr75 particles were associated with gradual and significant within-group decreases in the viability of SaOs-2 and HGF cells. These effects were less pronounced in the Zr group. Similar to control cells, THP-1 did not reveal any significant increases in IL-1 beta and IL-6 concentrations. Viability of THP-1 was merely impaired in the presence of Ti100.
\end{abstract}

Conclusions: Ti and Zr particles had a detrimental effect on the viability of SaOs-2 and HGF, but no proinflammatory effect on THP-1.

Keywords: Cellular immunology, Cytokines, Fibroblast, In vitro model, Monocytes, Osteoblast

\section{Background}

Recently, peri-implantitis was defined as "a plaqueassociated pathological condition occurring in tissues around dental implants, characterized by inflammation in the peri-implant mucosa and subsequent progressive loss of supporting bone." [1]. It was also anticipated that titanium (Ti) and metal particles may contribute to the pathogeneses of peri-implant disease [2, 3]. These particles can be released either by abrasion during implant insertion [4], micromovements at the implant-abutment interface $[5,6]$, or biocorrosion $[7,8]$. In fact, histological analyses of human biopsy material obtained at peri-implantitis sites suggested an association between the inflammatory cell infiltrate and detectable metal particles $[9,10]$. However, metal-like debris was also noted at healthy implant sites [11], thus questioning the role of titanium or metal particles in the pathogenesis of peri-implant diseases [12]. Nevertheless, several in vitro

\footnotetext{
* Correspondence: f.schwarz@med.uni-frankfurt.de

${ }^{1}$ Department of Oral Surgery and Implantology, Carolinum, Goethe

University, Frankfurt, Germany

${ }^{2}$ Department of Oral Surgery, Universitätsklinikum Düsseldorf, Düsseldorf,

Germany

Full list of author information is available at the end of the article
}

studies provide some evidence that microsized and nanosized titanium particles may induce cytotoxic effects [1316] and enhance pro-inflammatory responses [17-20].

Very limited data also suggest that particle release from implants made of yttria-stabilized tetragonal zirconia polycrystal (Zr) may induce similar cellular reactions [21, 22]. Since these implants reveal similar biological complications [23] as Ti implants, one may also have to question the potential role of $\mathrm{Zr}$ particles in the pathogenesis of peri-implant disease. A major limitation of currently available studies on both $\mathrm{Ti}$ and $\mathrm{Zr}$ particles is the lack of cell lineages with a major relevance to peri-implant tissues.

Therefore, the aim of the present study was to assess and compare the effects of differently sized $\mathrm{Ti}$ and $\mathrm{Zr}$ particles on (1) the viability of osteoblasts and fibroblasts and (2) the cytokine expression of monocytes in vitro.

\section{Methods}

\section{Titanium and zirconia particles}

Commercially pure $(99.9 \%)$ Ti particles exhibiting average particle sizes of either $60-80 \mathrm{~nm}$ (Ti60-80) or 100 $\mathrm{nm}$ (Ti100) as well as $\mathrm{Zr}$ particles of $2 \mu \mathrm{m}$ ( $\mathrm{Zr} 2)$ and 
$75 \mu \mathrm{m}$ (Zr75) (io-li-tec, Heilbronn, Germany) were used for the present analysis.

\section{Cell cultures}

Binding 96-well plates (Corning Inc., Acton, MA, USA) containing Ti60-80, Ti100, Zr2, and Zr75 particles (applied to homogeneously cover the well ground in a monolayer) as well as empty controls were seeded with human gingival fibroblasts (HGF; Provitro GmbH, Berlin, Germany) (6 wells per group, in duplicate), human osteogenic osteosarcoma cells (SaOs-2, DSMZ, Braunschweig, Germany) [3000 cells] (6 wells per group, in triplicate), and acute monocytic leukemia cells (THP-1, DSMZ, Braunschweig, Germany) [5000 cells] (5 wells per group) and cultured in $1 \mathrm{ml}$ of Dulbecco's modified Eagle's medium (DMEM; high glucose, GlutaMax, Sigma-Aldrich, Schnelldorf, Germany) with the supplement of $10 \%$ fetal bovine serum (FBS; Sigma-Aldrich) and 1\% penicillin/streptomycin.

One group of THP-1 cells was stimulated using phorbol 12-myristate 13 -acetate $(5 \mathrm{ng} / \mathrm{ml})$ (PMA; P81391MG, Merck KGaA, Darmstadt, Germany) and served as an additional control.

The cell culture conditions were set at a temperature of $37^{\circ} \mathrm{C}$ and a humidified atmosphere of $95 \%$ and $5 \% \mathrm{CO}_{2}$.

\section{Cell viability assay}

Cell viability was measured at days $0,2,4$, and 7 (HGF and SaOs-2) and days $0,1,2$, and 4 (THP-1) by the use of a luminescence assay (CellTiter-Glo; Promega, Mannheim, Germany) in a luminometer (Victor X3; Perkin-Elmer, Rodgau, Germany). This assay is based on a quantification of adenosinetriphosphate (ATP), signaling the presence of metabolic active cells. This is based on the luciferasecatalyzed reaction of luciferin and ATP. In particular, mono-oxygenation of luciferin is catalyzed by luciferase in the presence of $\mathrm{Mg}^{2+}$, ATP, and molecular oxygen. The luminescent signal was measured in counts per second (CPS).

\section{Enzyme-linked immunosorbent assays}

Enzyme-linked immunosorbent assays (ELISA) were used to determine human interleukin (IL)-1 beta and IL6 (Quantikine ${ }^{\bullet}$ ELISA kit, R\&D Systems Inc., Minneapolis, USA) concentrations at $24 \mathrm{~h}$ following incubation of Ti60-80, Ti100, Zr2, and ZR75 particles with PMA (5 $\mathrm{ng} / \mathrm{ml}$ )-stimulated THP-1 cells (DSMZ, Braunschweig, Germany) [5000 cells; in duplicate, binding 24-well plates with the same culture conditions as described above]. THP-1 seeded in empty wells served as cell controls. Recombinant human cytokines (Quantikine ${ }^{\circ} \mathrm{Im}$ munoassay Control Group 1, R\&D Systems Inc.) were used as additional positive controls (IL-1 beta, $40-79 \mathrm{pg} /$ $\mathrm{ml}$; IL-6, 80-98 pg/ml; TNF-alpha, 147-265 pg/ml).

Standard curves ( $x$-axis: IL-1 beta/IL-6/TNF-alpha concentrations in $\mathrm{pg} / \mathrm{ml} ; y$-axis: optical densities) were established according to the instructions given by the manufacturer (Quantikine ${ }^{\bullet}$ ELISA kit). Optical densities of each well were assessed using a microplate reader (Victor X3; Perkin-Elmer, Rodgau, Germany) at $450 \mathrm{~nm}$.

\section{Statistical analysis}

A software package (SPSS 24.0, SPSS Inc., Chicago, IL, USA) was used for the statistical analysis. Mean values, standard deviations, medians, min., and max. were calculated for each group. Analysis of variance (ANOVA) and post hoc testing using Bonferroni's correction for multiple comparisons was used for within-group comparisons of cell viability measurements. Comparisons of mean optical densities were accomplished using the unpaired $t$ test. Results were considered statistically significant at $P<0.05$.

\section{Results}

The viability of SaOs-2 and HGF cells in test and control groups expressed as luminescent output (median CPS) is presented in Figs. 1a-d.

\section{Cell viability assay SaOs-2}

In all test groups investigated, within-group comparisons revealed significant decreases of mean CPS values at days 2, 4, and 7 (Fig. 1a).

In particular, CPS in the Ti60-80 group decreased from $8109.28 \pm 3361.91$ ( $\min .4439 .0$, $\max .11039 .5)$ at day 0 to $672.9 \pm 248.05(\min .481 .0$, max. 953.0) at day $2(P=$ 0.004 ), to $113.44 \pm 43.54$ ( $\min$. 63.3, $\max .142 .0$ ) at day 4 $(P=0.002)$, and to $27.66 \pm 13.32$ (min. 17.3, max. 42.7) at day $7(P=0.002)$, respectively. In the Ti100 group, CPS decreased from $7907.67 \pm 2723.49$ (min. 5360.0, max. 10778.0) at day 0 to $87.54 \pm 69.51$ (min. 40.0, max. 167.0) at day $2(P=0.001)$, to $30.11 \pm 9.29(\min .23 .0, \max .41 .0)$ at day $4(P=0.001)$, and to $26.44 \pm 8.86$ (min. 16.0 , max. $33.0)$ at day $7(P=0.001)$, respectively.

Similar reductions were also noted in both $\mathrm{Zr}$ groups. In particular, CPS in the Zr2 group decreased from 14,368.1 \pm 6165.94 (min. 7463.0, max. 19324.0) at day 0 to $4141.89 \pm$ 937.53 (min. 3539.0, max. 5222.0) at day $2(P=0.025)$, to $1981.22 \pm 1013.28(\min .821 .0, \max .2690 .0)$ at day $4(P=$ 0.008 ), and to $245.34 \pm 139.78$ ( $\min .140 .0$, max. 404.0) at day $7(P=0.004)$, respectively. In the Zr75 group, CPS decreased from 15,072.0 \pm 2914.94 ( $\min .12620 .0$, max. 18295.0) at day 0 to $4532.88 \pm 2137.64$ ( $\min$. 2244.0, $\max .6478 .0$ ) at day 2 $(P=0.001)$, to $3192.78 \pm 1700.42(\mathrm{~min} .1235 .0$, max. 4305.0) at day $4(P=0.001)$, and to $425.80 \pm 84.72(\mathrm{~min} .366 .0$, max. $523.0)$ at day $7(P=0.001)$, respectively.

In contrast, the control wells were associated with significant (i.e., days 4 and 7) increases of mean CPS values from $100,043.20 \pm 15,695.83$ (min. 86363.0, max. 117179.0) at day 0 to $174,172.40 \pm 31,103.18$ (min. 141704.0, max. 203702.0) at day $2(P=1.00)$, to $346,257.23 \pm 27,639.35$ (min. 314427.0, max. 364188.0) at day $4(P=0.046)$, and to 

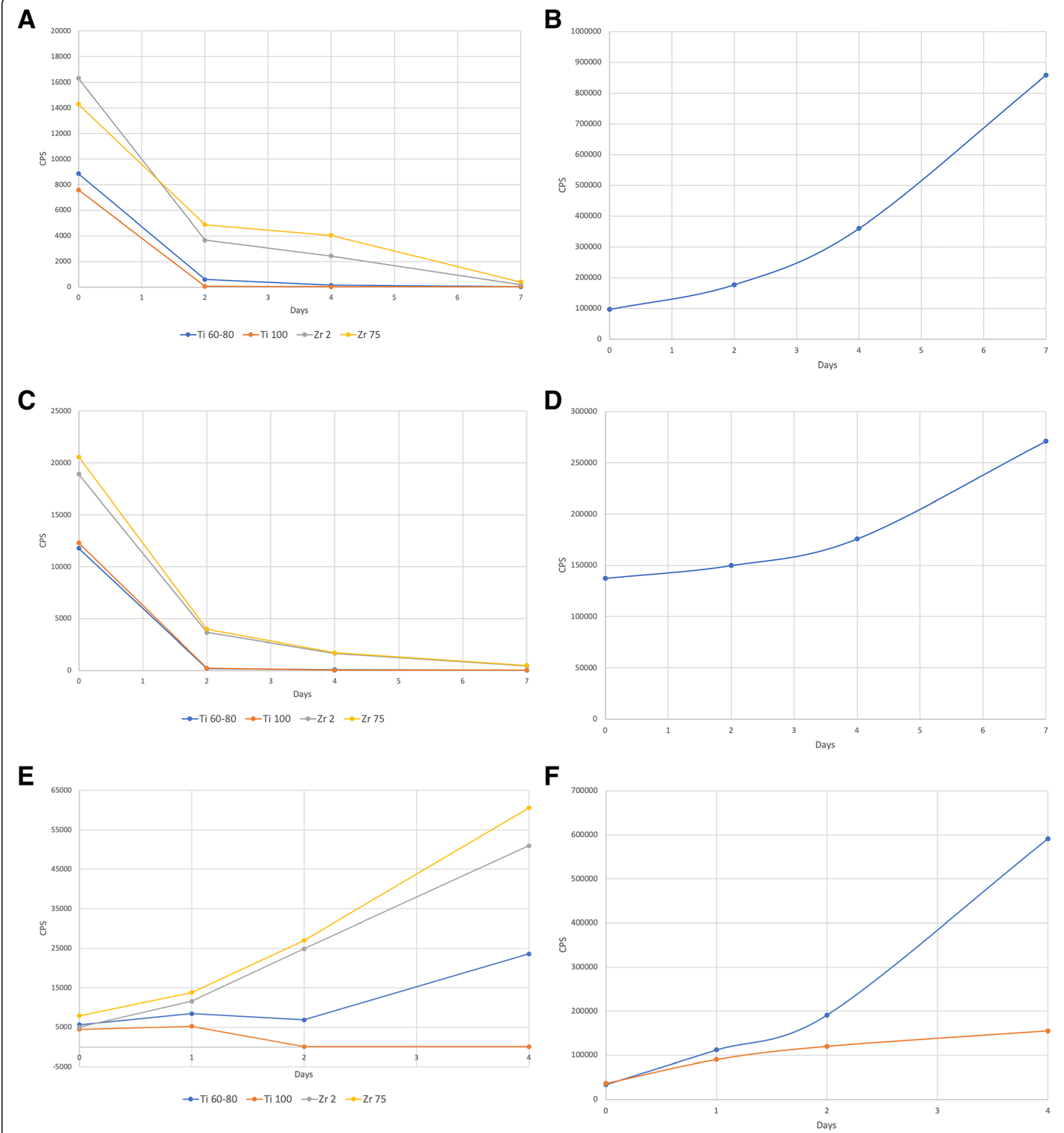

Fig. 1 Mitochondrial activity expressed as median luminescent output (counts per second -CPS) of SaOs-2 and HGF in different groups. a Test groups (SaOs-2). b Control group (SaOs-2). c Test groups (HGF). d Control group (HGF). e Test groups (THP-1). f Control groups (THP-1)

$828,144.28 \pm 164,532.45$ (min. 650621.0, $\max .975516 .0)$ at day $7(P=0.001)$, respectively (Fig. $1 \mathrm{~b})$.

\section{Cell viability assay HGF}

When compared with day 0 , all particles investigated were associated with significant within-group decreases of mean CPS values at days 2, 4, and 7 (Fig. 1c).
In particular, CPS in the Ti60-80 group decreased from $11,785.25 \pm 2311.46$ (min. 10150.8, max. 13419.7) at day 0 to $202.85 \pm 139.79$ (min. 104.0. $\max .301 .7)$ at day $2(P=$ 0.003 ), to $82.00 \pm 44.26$ ( $\min .50 .7$, $\max .113 .3$ ) at day 4 $(P=0.003)$, and to $34.35 \pm 14.63$ (min. 24.0, $\max .44 .7)$ at day $7(P=0.003)$, respectively. In the Ti100 group, CPS decreased from 12,303.55 \pm 3716.90 (min. 9675.0, max. 
14932.0) at day 0 to $209.35 \pm 109.81$ (min. 132.0, max. $287.0)$ at day $2(P=0.017)$, to $29.65 \pm 8.41$ (min. 24.0, max. 36.0) at day $4(P=0.016)$, and to $26.50 \pm 8.76$ (min. 20.0, max. 33.0) at day $7(P=0.016)$, respectively.

Mean CPS decreases were lower in both $\mathrm{Zr}$ groups. In particular, CPS in the Zr2 group decreased from 18, $923.80 \pm 10,591.04$ (min. 11435.0, max. 26413.0) at day 0 to $3658.50 \pm 64.34(\min .3613 .0, \max .3704 .0)$ at day 2 $(P=0.272)$, to $1644.35 \pm 761.76$ (min. 1106.0, max. 2183.0) at day $4(P=0.188)$, and to $439.95 \pm 189.01$ (min. 306.0, max. 574.0) at day $7(P=0.152)$, respectively. In the Zr75 group, CPS decreased from 20,572.0 \pm 6662.64 (min. 15861.0, max. 25283.0) at day 0 to $3968.50 \pm$ 2585.46 (min. 2140.0, max. 5797.0) at day $2(P=0.059)$, to $1711.00 \pm 542.63$ (min. 1327.0, max. 2095.0) at day 4 $(P=0.037)$, and to $499.30 \pm 161.22$ (min. 385.0, max. 613.0) at day $7(P=0.030)$, respectively.

In contrast, the control wells were associated with increases of mean CPS values from 137,319.90 $\pm 16,984.13$ (min. 125310.0, max. 149330.0) at day 0 to $149,859.90 \pm$ $14,552.11$ (min. 139570.0, max. 160150.0) at day $2(P=$ 1.000 ), to $175,868.30 \pm 12,545.48$ (min. 166997.0, $\max$. $184739.0)$ at day $4(P=1.000)$, and to $271,069.35 \pm 76$, 582.98 (min. 216917.0, max. 325222.0) at day $7(P=$ 0.178), respectively (Fig. 1d).

\section{Cell viability assay THF-1}

When compared with day 0, Ti60-80, Zr2, and Zr75 particles were associated with increases of mean CPS values, reaching statistical significance at days 2 (Zr2 and Zr75) and 4 (Ti60-80, Zr2, and Zr75), respectively. In particular, mean CPS values in the Ti60-80 group increased from $5640.40 \pm 741.96$ (min. 4364.0, $\max .6206 .0$ ) at day 0 to $8435.60 \pm 2850.84(\min .3478 .0, \max .10460 .0)$ at day 1 $(P=1.000)$. At day 2 , mean CPS values decreased to $6845.60 \pm 6332.99$ (min. 36.0, max. 13362.0) $(P=1.000)$, but further increased to $23,615.40 \pm 7678.70$ (min. 14789.0, max. 34061.0) at day $4(P<0.001)$, respectively.

A more steady and pronounced increase in cell viability was noted in both $\mathrm{Zr} 2 / \mathrm{Zr} 75$ groups, resulting in changes of mean CPS values from 5014.80 \pm 989.10 (min. 3786.66, max. 6242.94)/7880.00 \pm 892.51 (min. 6771.79, $\max$. $8988.21)$ at day 0 to $50,980.60 \pm 10,504.14$ (min. 37937.98, $\max .64023 .22) / 60,586.60 \pm 3306.45(\min .56481 .10$, $\max$. 64692.10) at day $4(P<0.001)$, respectively (Fig. $1 \mathrm{e})$.

In contrast, after a slight initial increase from $4439.20 \pm$ 1571.87 (min. 2487.46, max. 6390.94) at day 0 to $5259.60 \pm 5984.03$ (min. - 2170.56, max. 12689.76) at day $1(P=1.000)$, Ti100 particles were associated with marked decreases of mean CPS values at days 2 (52.80 \pm 15.65 , min. 33.36, max. 72.24) $(P=0.237)$ and $4(84.80 \pm 106.94$, min. -47.99 , max. 217.59) $(P=0.245)$, respectively.

In both control groups (THP-1 with and without PMA stimulation), within-group comparisons revealed significant increases of mean CPS values at days 1,2 , and $4(P<$ $0.001)$, respectively. However, these increases in THP1 viability were markedly lower following PMA stimulation (Fig. 1f).

\section{IL-1 beta and IL-6 ELISA}

The optical density of IL-1 beta measurements was $0.047 \pm 0.002$ (median 0.046) in the Ti60-80 group, $0.046 \pm 0.001$ (median 0.047 ) in the Ti100 group, $0.047 \pm$ 0.004 (median 0.046) in the Zr2 group, and $0.046 \pm 0.003$ (median 0.046) in the Zr75 group, respectively. These values were comparable to those noted in the respective control group $(0.053 \pm 0.006$, median 0.053$)(P>0.05$, respectively). Measurements of positive controls amounted to $0.43 \pm 0.006$ (median 0.43 ).

The optical density of IL- 6 measurements was $0.040 \pm$ 0.002 (median 0.040 ) in the Ti60-80 group, $0.038 \pm 0.038$ (median 0.038 ) in the Ti100 group, $0.040 \pm 0.005$ (median 0.04) in the Zr2 group, and $0.044 \pm 0.001$ (median 0.044) in the Zr75 group, respectively. These values were comparable to those noted in the respective control group $(0.043 \pm 0.001$, median 0.043) $(P>0.05$, respectively). Measurements of positive controls amounted to $0.37 \pm 0.006$ (median 0.37).

\section{Discussion}

The present study was designed to investigate the effects of differently sized $\mathrm{Ti}$ and $\mathrm{Zr}$ particles on the viability of SaOs-2 osteoblasts and HGFs as well as the viability and cytokine expression of THP-1.

When compared with the respective control groups, it was observed that all particles investigated had a detrimental effect on the viability of SaOs-2 and HGF cells, as evidenced by significant reductions in mean CPS values. In contrast, the viability of THP-1 was merely impaired in the presence of Ti100. In this context, it must be emphasized that the luminescent signal, generated during cell lysis, is proportional to the amount of ATP present and therefore directly correlates with the number of viable cells [24].

To the best of our knowledge, these are the first in vitro analyses employing two cell lineages with a major relevance to peri-implant tissues (i.e., gingival fibroblasts, osteoblasts).

Basically, however, the present viability assessment corroborates previous analyses on the cytotoxicity of $\mathrm{Ti}$ particles [13-16]. In particular, Choi et al. [16] also reported on a significant decrease of the viability of osteoblasts at $72 \mathrm{~h}$ following incubation with differently sized $\mathrm{Ti}$ particles (i.e., $<1.5, \geq 1.5$, and $<5.0 \mu \mathrm{m}$; $\geq 5.0$ and $<10.0 \mu \mathrm{m}$; and $\geq 10.0$ and $<15.0 \mu \mathrm{m})$. Moreover, it was noted that particles of $<1.5 \mu \mathrm{m}$ and up to $5.0 \mu \mathrm{m}$ were clearly identifiable in the cytoplasm, whereas larger particle sizes were attached to the 
plasma membrane [16]. In this context, it must be emphasized that SaOs-2 cells as employed in the present analysis were characterized as osteoblast-like cells $[25,26]$, responding in a similar way to implant surfaces as primary human osteoblasts [27].

Comparable outcomes were also noted for a human pulmonary endothelial cell line and THP-1, also revealing that larger $\mathrm{Ti}$ particles had a more intense and negative effect on cell viability at $24 \mathrm{~h}$ than smaller particles (596 vs. $166 \mathrm{~nm}$ ) [13].

Similarly, nanosized (20-250 nm) Ti particles were associated with a higher uptake and cytotoxic effects in periodontal ligament fibroblasts than microsized $(0.3-43 \mu \mathrm{m})$ Ti particles [14]. This was also confirmed by Cai et al. [15] pointing to the highest cytotoxic effect of Ti nanoparticles that were within the range of $100 \mathrm{~nm}$.

When further analyzing the present data, it was also observed the CPS reductions in HGF were commonly less pronounced when exposed to $\mathrm{Zr}$ particles, as compared with both Ti groups.

In this context, it must be emphasized that a major limitation of the present analysis was the lack of nanoscaled $\mathrm{Zr}$ particles. These particles, however, had also been obtained for this analysis, but due to electrostatic phenomena, their transfer to the well plates could not be accomplished. Nevertheless, the aforementioned data on the cytotoxic influence of different particle sizes may at least in part explain the higher mean CPS values in $\mathrm{Zr} 2$ and $\mathrm{Zr} 75$ groups.

On the contrary, however, the results of an experimental animal study provide some evidence that Ti microparticles were associated with a higher increase in $\mathrm{O} 2$ - generation in macrophages than $\mathrm{Zr}$ particles, suggesting that their biocompatibility may have also been influenced by the "shape and/or crystal structure" of the metal itself [22].

The present analysis of cytokine expressions in THP-1 failed to corroborate recent findings on an enhanced proinflammatory response following exposure of THP-1 or macrophages to Ti particles [17-20].

In particular, Taira et al. [20] observed a high-level expression of IL-1 beta, IL-6, and TNF-alpha in THP1 at $24 \mathrm{~h}$. Similar responses were also noted in macrophages $[17,19]$. When interpreting these discrepancies, one has to realize that a monocyte-like cell line, derived from acute monocytic leukemia cells (i.e., THP-1), may behave differently from primary macrophages [28]. Moreover, in peri-implant granulation tissue fibroblasts, an increase in the gene expression of IL-6, IL-8, and TNF-alpha was just measured when $\mathrm{Ti}$ particles were applied in sub-toxic doses [18]. Since none of the particles investigated in the present study were shown to impair the viability of stimulated THP-1 cells at day 1 , one may assume that the absence of a cytokine expression was not caused by any cytotoxic effects.
Within its limitations, the present in vitro analysis revealed that $\mathrm{Ti}$ and $\mathrm{Zr}$ particles had a detrimental effect on the viability of SaOs-2 and HGF, but no proinflammatory effect on THP-1. These findings need to be validated in vivo.

\section{Acknowledgements}

None.

\section{Authors' contributions}

FS, RS, and JB have made substantial contributions to the study conception, acquisition, and interpretation of the data as well as the manuscript preparation. $\mathrm{ML}, \mathrm{TH}$, and $\mathrm{BH}$ were involved in the data acquisition, data management, and analysis as well as the statistical analysis.

\section{Funding}

The study was funded by the authors own departments.

\section{Availability of data and materials}

The availability of raw data used and/or analyzed during the current study is limited/restricted by general data protection regulations.

Ethics approval and consent to participate

This article does not contain any studies with human participants or animals performed by any of the authors.

\section{Consent for publication}

For this type of study, formal consent is not required.

\section{Competing interests}

Frank Schwarz, Maike Langer, Tina Hagena, Brigitte Hartig, Robert Sader, and Jürgen Becker declare that they have no competing interests related to this analysis.

\section{Author details}

'Department of Oral Surgery and Implantology, Carolinum, Goethe University, Frankfurt, Germany. ${ }^{2}$ Department of Oral Surgery, Universitätsklinikum Düsseldorf, Düsseldorf, Germany. ${ }^{3}$ Department for Oral, Cranio-Maxillofacial and Facial Plastic Surgery, Medical Center of the Goethe University Frankfurt, Frankfurt am Main, Germany.

Received: 24 January 2019 Accepted: 17 June 2019

Published online: 09 July 2019

\section{References}

1. Berglundh T, Armitage G, Araujo MG, et al. Peri-implant diseases and conditions: consensus report of workgroup 4 of the 2017 world workshop on the classification of periodontal and Peri-implant diseases and conditions. J Clin Periodontol. 2018;45:286-91.

2. Fretwurst T, Nelson K, Tarnow DP, Wang HL, Giannobile WV. Is metal particle release associated with Peri-implant bone destruction? An emerging concept. J Dent Res. 2018;97:259-65.

3. Noronha Oliveira M, Schunemann WVH, Mathew MT, et al. Can degradation products released from dental implants affect peri-implant tissues? J Periodontal Res. 2018:53:1-11.

4. Senna P, Antoninha Del Bel Cury A, Kates S, Meirelles L. Surface damage on dental implants with release of loose particles after insertion into bone. Clin Implant Dent Relat Res. 2015;17:681-92.

5. Sikora CL, Alfaro MF, Yuan JC, Barao VA, Sukotjo C, Mathew MT. Wear and corrosion interactions at the titanium/zirconia Interface: dental implant application. J Prosthodont. 2018. https://doi.org/10.1111/jopr.12769 Epub ahead of print.

6. Stimmelmayr M, Edelhoff D, Guth JF, Erdelt K, Happe A, Beuer F. Wear at the titanium-titanium and the titanium-zirconia implant-abutment interface: a comparative in vitro study. Dent Mater. 2012;28:1215-20.

7. Mareci D, Chelariu R, Gordin DM, Ungureanu G, Gloriant T. Comparative corrosion study of Ti-ta alloys for dental applications. Acta Biomater. 2009;5:3625-39.

8. Barao VA, Mathew MT, Assuncao WG, Yuan JC, Wimmer MA, Sukotjo C. Stability of cp-Ti and Ti-6Al-4V alloy for dental implants as a function of saliva pH - an electrochemical study. Clin Oral Implants Res. 2012;23:1055-62. 
9. Wilson TG Jr, Valderrama P, Burbano M, et al. Foreign bodies associated with peri-implantitis human biopsies. J Periodontol. 2015;86:9-15.

10. Fretwurst T, Buzanich G, Nahles S, Woelber JP, Riesemeier H, Nelson K. Metal elements in tissue with dental peri-implantitis: a pilot study. Clin Oral Implants Res. 2016;27:1178-86.

11. Olmedo DG, Nalli G, Verdu S, Paparella ML, Cabrini RL. Exfoliative cytology and titanium dental implants: a pilot study. J Periodontol. 2013;84:78-83.

12. Schwarz F, Derks J, Monje A, Wang H-L. Peri-implantitis. J Clin Periodontol. 2018:45:246-66.

13. Okuda-Shimazaki J, Takaku S, Kanehira K, Sonezaki S, Taniguchi A. Effects of titanium dioxide nanoparticle aggregate size on gene expression. Int J Mol Sci. 2010;11:2383-92.

14. He X, Hartlieb E, Rothmund L, et al. Intracellular uptake and toxicity of three different titanium particles. Dent Mater. 2015;31:734-44.

15. Cai K, Hou Y, Hu Y, et al. Correlation of the cytotoxicity of TiO2 nanoparticles with different particle sizes on a sub-200-nm scale. Small. 2011;7:3026-31.

16. Choi MG, Koh HS, Kluess D, et al. Effects of titanium particle size on osteoblast functions in vitro and in vivo. Proc Natl Acad Sci U S A. 2005;102:4578-83.

17. Eger $\mathrm{M}$, Sterer $\mathrm{N}$, Liron T, Kohavi D, Gabet Y. Scaling of titanium implants entrains inflammation-induced osteolysis. Sci Rep. 2017;7:39612.

18. Irshad M, Scheres N, Crielaard W, Loos BG, Wismeijer D, Laine ML. Influence of titanium on in vitro fibroblast-Porphyromonas gingivalis interaction in peri-implantitis. J Clin Periodontol. 2013;40:841-9.

19. Pettersson M, Kelk P, Belibasakis GN, Bylund D, Molin Thoren M, Johansson A. Titanium ions form particles that activate and execute interleukin-1 beta release from lipopolysaccharide-primed macrophages. J Periodontal Res. 2017:52:21-32

20. Taira M, Kagiya T, Harada $\mathrm{H}$, et al. Microscopic observations and inflammatory cytokine productions of human macrophage phagocytising submicron titanium particles. J Mater Sci Mater Med. 2010;21:267-75.

21. Hempel U, Hefti T, Kalbacova M, Wolf-Brandstetter C, Dieter P, Schlottig F. Response of osteoblast-like SAOS-2 cells to zirconia ceramics with different surface topographies. Clin Oral Implants Res. 2010;21:174-81.

22. Olmedo DG, Tasat DR, Evelson P, Rebagliatti R, Guglielmotti MB, Cabrini RL. In vivo comparative biokinetics and biocompatibility of titanium and zirconium microparticles. J Biomed Mater Res Part A. 2011;98:604-13.

23. Becker J, John G, Becker K, Mainusch S, Diedrichs G, Schwarz F. Clinical performance of two-piece zirconia implants in the posterior mandible and maxilla: a prospective cohort study over 2 years. Clin Oral Implants Res. 2017;28:29-35.

24. Crouch SP, Kozlowski R, Slater KJ, Fletcher J. The use of ATP bioluminescence as a measure of cell proliferation and cytotoxicity. J Immunol Methods. 1993;160:81-8.

25. Murray E, Prowedini D, Curran D, Catherwood B, Sussman H, Manolagas S. Characterization of a human osteoblastic osteosarcoma cell line (SAOS-2) with high bone alkaline phosphatase activity. J Bone Miner Res. 1987;2:231-8.

26. Rodan SB, Imai Y, Thiede MA, et al. Characterization of a human osteosarcoma cell line (Saos-2) with osteoblastic properties. Cancer Res. 1987:47:4961-6.

27. Ahmad M, McCarthy MB, Gronowicz G. An in vitro model for mineralization of human osteoblast-like cells on implant materials. Biomaterials. 1999;20:211-20.

28. Bosshart H, Heinzelmann M. THP-1 cells as a model for human monocytes. Ann Transl Med. 2016:4:438.

\section{Publisher's Note}

Springer Nature remains neutral with regard to jurisdictional claims in published maps and institutional affiliations.

\section{Submit your manuscript to a SpringerOpen ${ }^{\circ}$ journal and benefit from:}

- Convenient online submission

- Rigorous peer review

- Open access: articles freely available online

- High visibility within the field

- Retaining the copyright to your article

Submit your next manuscript at $\boldsymbol{\nabla}$ springeropen.com 